Article

\title{
Characteristics of Self-Healable Copolymers of Styrene and Eugenol Terminated Polyurethane Prepolymer
}

\author{
Jing-Yu Liang ${ }^{1,+}$, Se-Ra Shin ${ }^{1,+}+$, , Soo-Hyoung Lee ${ }^{1, *}$ and Dai-Soo Lee ${ }^{2, * \mathbb{C}}$ \\ 1 Department of Semiconductor and Chemical Engineering, Chonbuk National University, 567 Baekje-daero, \\ Deokjini-gu, Jeonju 54896, Korea; liangjy@naver.com (J.-Y.L.); srshin89@jbnu.ac.kr (S.-R.S.) \\ 2 Research Institute of Future Energy, Chonbuk National University, 567 Baekje-daero, Deokjini-gu, \\ Jeonju 54896, Korea \\ * Correspondence: shlee66@jbnu.ac.kr (S.-H.L.); daisoolee@jbnu.ac.kr (D.-S.L.); \\ Tel.: +82-63-270-2435 (S.-H.L); +82-63-270-2310 (D.-S.L.) \\ + Contributed equally to this work.
}

Received: 22 August 2019; Accepted: 11 October 2019; Published: 14 October 2019

check for updates

\begin{abstract}
With limited biomass that can be currently utilized as a renewable resource, it is important to develop a method to convert biomass into materials that can replace fossil fuel product. In this paper, eugenol, a bio-based allyl chain-substituted guaiacol, was used to synthesize self-healable copolymers. Eugenol terminated polyurethane prepolymer (ETPU) was synthesized from eugenol and polyurethane prepolymers terminated with isocyanate groups. ETPU contained two allyl groups. Self-healing copolymer networks were obtained by copolymerization of ETPU and styrene monomer via free radical polymerization. Effects of ETPU content on the properties of copolymers were then studied. These copolymers containing ETPU exhibited good thermal stability and mechanical properties. These copolymers showed higher tensile strength and elongation at break than PS. Their maximum tensile strength reached $19 \mathrm{MPa}$. In addition, these copolymers showed self-healing property at elevated temperature due to the reversible nature of urethane units in ETPU.
\end{abstract}

Keywords: eugenol; styrene; self-healing; copolymers; polyurethane prepolymer

\section{Introduction}

Due to continuously increasing price of petroleum resources and increase in environmental awareness, biomass derived from renewable resources has attracted a great deal of attention. For the practical applications of the biomass for polymers, efforts to find advantages in cost, performance, and LCA are necessary. Several biomasses have been proposed to prepare new bio-based materials, including vegetable oils [1], fatty acids [2], lignin [3], vanillin [4], succinic acid [5], and eugenol [6].

Self-healing is a process of healing microcracks to extend the safety and working life of polymeric materials. So far, major findings in this field can be divided into two categories: extrinsic and intrinsic self-healing [7]. The extrinsic healing system includes microcapsules or hollow fibers releasing healing agents after crack formation. The intrinsic healing is based on reversible covalent or non-covalent supramolecular interactions. Non-covalent methods are based on hydrogen bonding [8], ionic interactions, or metal-ligand interaction [9]. However, non-covalent bonding-based polymers showed weak mechanical properties [10]. Thus, reversible dynamic covalent bonds such as disulfide bonds [11], nitroxide bonds [12], acylhydrazone bonds [13], Diels-Alder (DA) reaction products [14], urethane bonds [15], and reversible ester bonds [16] have been receiving increasing attention. These reversible covalent bonds can especially contribute to the healing ability of polymers by various stimuli. 
Polyurethanes (PUs) are among the most important polymeric materials. Having a wide range of density, hardness, and stiffness, they have been widely used as adhesives, foams, and coatings. The PUs prepared from three main components, long chain diols (polyols), diisocyanates (aromatic or aliphatic types) and short chain diols (chain extenders) are segmented copolymers of hard and soft segment domains. Recently, many studies have focused on the self-healing properties of PUs [17-19]. Self-healing PUs repair damage by the release of healing agents or temporary increased mobility. There are many different types of polyols, chain extenders, and isocyanates, so the choices of self-healing mechanism for PUs are diverse. The success of the healing capability depends on the characteristics of the dynamic nature of the structures. For the reversible covalent bonds, DA reaction product is probably widely known. Feng et al. studied a new thermoplastic polyurethane (TPU) with excellent self-healing performance due to the incorporated DA reaction products, and the cracks in polyurethane films could be repaired by dual actions of thermo-reversible DA reaction and thermal movement of molecular chains [20]. Lin and co-workers synthesized crosslinker with maleimide groups and used in the reactions with the pendant furan groups of PU to prepare the self-healing electrically conductive composites based on DA reaction [21]. Polymers with disulfide groups can undergo self-healing even at room temperature. Kim and co-workers developed a transparent and quickly self-healing TPU at room temperature due to the aromatic disulfide structure [22]. Yangisawa reported complete healing of PU elastomer at $36^{\circ} \mathrm{C}$ via hydrogen bonding of thiourea [23]. Urethane bonds in traditional PUs are made from hydroxyl groups of polyols, and various polyisocyanates. These bonds are reversible at elevated temperature $[24,25]$. When polyisocyanate reacts with aliphatic hydroxyls, PUs that contains thermodynamically stable bonds can be formed. Temperatures for the retro reactions of urethanes are important factors that allow self-healing of PUs. It should be as low as possible. The main dissociation pathway depends on the equilibrium between urethane bond and the starting functional group. When temperature increases, reverse reaction occurs. Electronic effect of substituents also influences the kinetics and equilibrium of thermally reversible reactions of urethane bonds. Aromatic hydroxyl group-based PUs favor the reverse reaction. According to reactivity classification, thermal dissociation temperatures are in the following order: alkyl-NCO/alkyl-OH $\left(250^{\circ} \mathrm{C}\right)>\operatorname{aryl}-\mathrm{NCO} / \mathrm{alkyl}-\mathrm{OH}\left(200^{\circ} \mathrm{C}\right)$ $>$ alkyl-NCO/aryl-OH $\left(180^{\circ} \mathrm{C}\right)>$ aryl-NCO/aryl-OH $\left(120^{\circ} \mathrm{C}\right)$ [26]. Phenolic hydroxyl can react with isocyanate to form phenolic urethane that can undergo dissociations into phenol and isocyanate due to the dynamic natures.

Eugenol (4-allyl-2-methoxyphenol) is a natural allyl chain-substituted guaiacol with allyl group extracted from lignocellulosic biomass. It can also be obtained from pyrolysis $[27,28]$ or depolymerization [29] of lignin. It is a relatively cheap bio-based compound with multi-reactive groups. It has great potential to be widely used in polymers due to its unique structure, abundant availability, and low cost. Eugenol is also used in perfumes, antioxidants, drugs, and foods [30]. In recent years, eugenol has attracted major interest in the development of bio-based polymers. Considering its potential abundant production and unique structure which includes methoxy-substituted phenolic ring and allyl group, it has been regarded as an ideal candidate to synthesize petroleum-based compounds such as thermosetting resins [31], benzoxazines resins [32], and epoxy resins [33].

Polystyrene (PS) is clear, hard, and brittle, but slow to biodegrade [34]. Therefore, it has been a focus of controversy among environmentalists. Styrene can easily copolymerize with different monomers such as acrylonitrile, acrylic monomers, butadiene, maleic anhydride, unsaturated polyesters, and others to create polymeric materials with unique properties suitable for many industrial applications [35-37]. In order to improve the processing, performance, and elasticity of plastic materials, polar and non-polar additives such as plasticizing modifiers can be added, resulting in materials with lower moduli, stiffness, and glass transition temperature. Meanwhile, elongation ability and polymer chain flexibility of materials are significantly increased [38,39]. In recent years, the utilization of eco-friendly modifiers such as epoxidized vegetable oils, biodiesel oils, hydrogenated Castrol oil, citrate esters, and poly (ethylene glycol) of low molecular weight has been investigated [40-42]. 
In this study, thermal and mechanical properties of PS modified with eugenol derivatives were investigated to impart toughness and self-healing capability to PS. Especially, eugenol terminated polyurethane prepolymers (ETPU) containing two vinyl groups at both ends were synthesized. Through free-radical polymerization process, copolymers of ETPU and styrene monomer were prepared. The influence of ETPU on copolymers was studied. Thermal properties, mechanical properties, and self-healing properties of these copolymers were investigated. Copolymers with aromatic urethane bonding structures showed considerable reverse reactions and implement the self-healing properties. It is postulated that ETPU can give vinyl polymers self-healing properties by copolymerizations due to the dynamic nature of urethane units based on eugenol.

\section{Experimentals}

\subsection{Materials}

Poly (tetramethylene ether glycol) (PTMEG1000) (Number average molecular weight: 1000g/mol, 99\%), eugenol (99\%), styrene monomer (SM, 99\%), dibutyltin dilaurate (DBTDL, 95\%), and tert-butyl peroxybenzoate (TBPB, 98\%), purchased from Sigma-Aldrich Chemical (Yongin City, Korea). And 4,4'-Methylene bis(phenyl isocyanate) (MDI, 99\%) was obtained from BASF (BASF Korea, Yeosu, Korea). Dimethylformamide (DMF, 99\%) was supplied by Samchun Pure Chemical (Pyeongtaek-si, Korea).

\subsection{Synthesis of Eugenol-terminated Polyurethane (ETPU)}

In a $500 \mathrm{~mL}$ round-bottomed flask, PTMEG-1000 (200 g, $0.2 \mathrm{~mol})$ and MDI (100 g, $0.4 \mathrm{~mol})$ were mixed and stirred at $60^{\circ} \mathrm{C}$ under $\mathrm{N}_{2}$ gas environment. After the mixture became homogeneous, the temperature was kept at $60^{\circ} \mathrm{C}$ and reaction proceeded without any solvent or catalyst. With continued stirring until NCO $\%$ reached the theoretical value based on the stoichiometry, eugenol (65.6 $\mathrm{g}, 0.4 \mathrm{~mol})$ and DBTDL $(0.73 \mathrm{~g}, 0.2 \mathrm{wt} . \%$ based on the total weight of mixture) were added into PU prepolymers. After mixing and stirring at $70{ }^{\circ} \mathrm{C}$ for about $5 \mathrm{~h}$, the isocyanate group completely reacted (NCO \% below $0.1 \%$ ). NCO \% was determined following ASTM D1638-74. Preparation route and ETPU chemical structure are shown in Scheme 1.

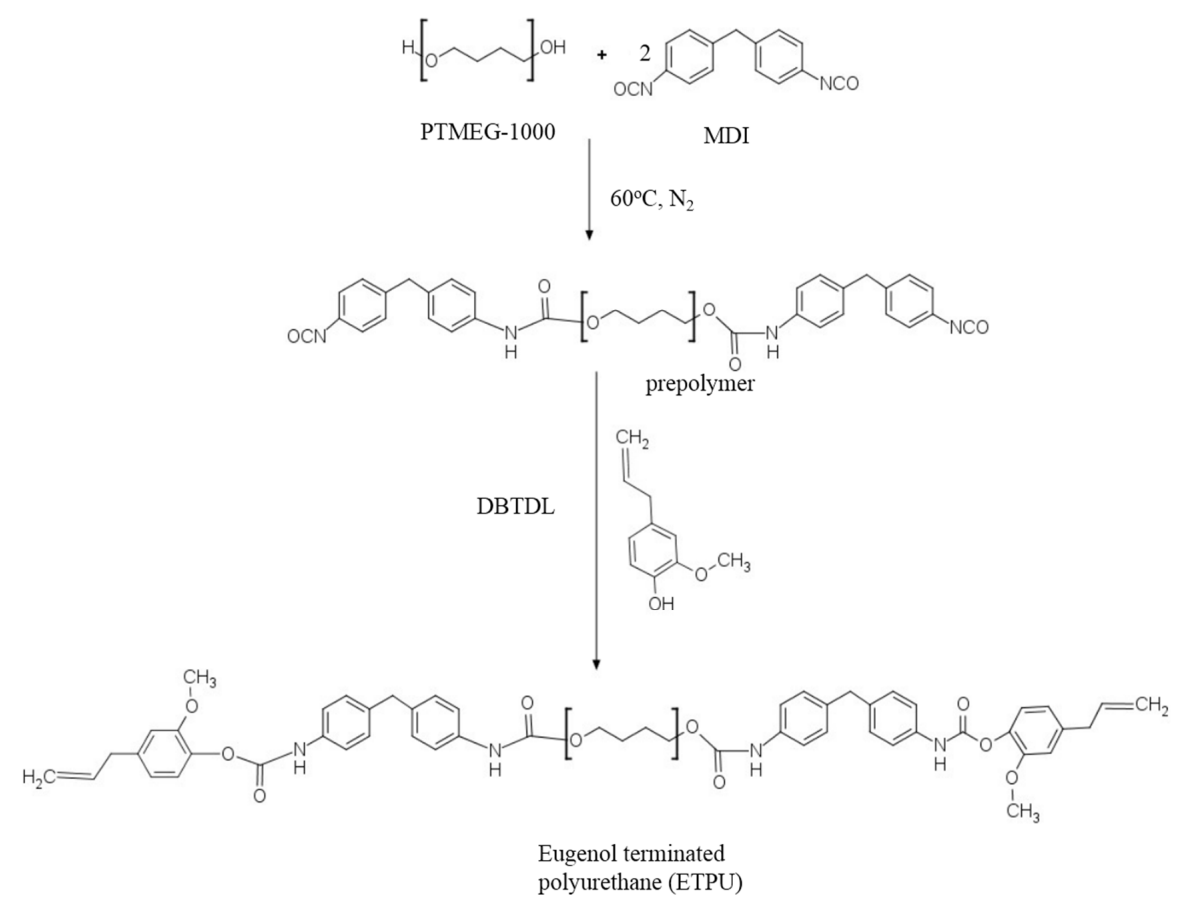

Scheme 1. Synthesis and structure of eugenol-terminated polyurethane prepolymer. 


\subsection{Preparation of Copolymers}

Detailed formulations of copolymers are shown in Table 1. In this experiment, TBPB (1 wt.\% based on total weight of monomer mixtures) was used as an initiator. Different contents of styrene monomers were mixed with ETPU. These mixtures of SM and ETPU were stirred at $100^{\circ} \mathrm{C}$ for several minutes to obtain a homogeneous solution. After pouring into silicon film molds, they were cured at $110^{\circ} \mathrm{C}$ in a convection oven for 1 day. Chemical structures of copolymers are shown in Scheme 2.

Table 1. Feed composition of copolymers.

\begin{tabular}{|c|c|c|c|c|}
\hline \multirow{2}{*}{ Sample Codes } & \multirow{2}{*}{$\begin{array}{c}\text { Monomer } 1 \\
\text { Styrene (mol) }\end{array}$} & \multirow{2}{*}{$\begin{array}{l}\text { Monomer } 2 \\
\text { ETPU (mol) }\end{array}$} & \multicolumn{2}{|c|}{ ETPU Content } \\
\hline & & & $\mathrm{mol} \%$ & wt. $\%$ \\
\hline PS & 10 & 0 & 0 & 0 \\
\hline $\mathrm{CP} 1$ & 9.8 & 0.2 & 2 & 26.4 \\
\hline $\mathrm{CP} 2$ & 9.6 & 0.4 & 4 & 42.3 \\
\hline $\mathrm{CP} 3$ & 9.1 & 0.9 & 9 & 63.5 \\
\hline
\end{tabular}<smiles>C=COC=Cc1cccc(C=C)c1</smiles>

ETPU styrene<smiles>[R]C(CC)C(C)CC(C)C(C)C(C)C</smiles>

copolymers<smiles>[R]Cc1ccc(OC(=O)Nc2ccc(Cc3ccc(NC(=O)C(C)(C)CCCCCCC(C)(C)OC(=O)Nc4ccc(Cc5ccc(NC(=O)Oc6ccc(CC)cc6OC)cc5)cc4)cc3)cc2)c(OC)c1</smiles>

Scheme 2. Synthesis and structures of crosslinked copolymers.

\subsection{Characterizations}

To confirm ETPU synthesis and identify the isocyanate group released by the reversible reaction of urethane at elevated temperatures $\left(100-200^{\circ} \mathrm{C}\right)$, the copolymers were analyzed by FT-IR spectroscopy (FT-IR-302, Jasco, Tokyo, Japan). Differential scanning calorimetry was performed using a Q20 DSC from TA instrument (New Castle, DE, USA) with heating rate of $10 \mathrm{~min}^{-1}$ from $-80{ }^{\circ} \mathrm{C}$ to $200{ }^{\circ} \mathrm{C}$ in nitrogen gas environment. Thermogravimetric analysis (TGA) was performed using Q500 TGA from TA instrument (New Castle, DE, USA) under the following condition: heating rate of $20^{\circ} \mathrm{C}$ / min, temperature range of $20-800{ }^{\circ} \mathrm{C}$, sample weight range of $10-20 \mathrm{mg}$, and nitrogen flow at $60 \mathrm{~mL} / \mathrm{min} .{ }^{1} \mathrm{H}$-nuclear magnetic resonance (NMR) was performed using a $600 \mathrm{MHz}$ JNM-ECA600 spectrometer (600 MHz, JNMECA600, JEOL, Tokyo, Japan) with $\mathrm{CDCl}_{3}$ as solvent. Tensile properties and self-healing efficiency were measured using a universal testing machine (UTM, LR5K Plus from LLOYD, West Sussex, UK). Measurements were carried out at $25^{\circ} \mathrm{C}$ with cross-head speed of 500 $\mathrm{mm} \mathrm{min}^{-1}$ following the ASTM-D638 method. Dynamic mechanical analysis (DMA) was conducted using a Q800 from TA instrument (New Castle, DE, USA). The dimension of sample size was $16 \mathrm{~mm} \times$ $5 \mathrm{~mm} \times 1.5 \mathrm{~mm}$ and the heating rate was $5^{\circ} \mathrm{C} \mathrm{min}-1$ from $-100{ }^{\circ} \mathrm{C}$ to $200{ }^{\circ} \mathrm{C}$ and the frequency was set at $1 \mathrm{~Hz}$. Atomic force microscope (AFM, Multimode-8, Bruker, Billerica, USA) was employed to observe morphologies of the copolymers. Self-healing abilities of films were observed with an optical 
microscope with fluorescence filters coupled with a digital camera. Fresh cuts were made using a sharp blade on surfaces of films. They were placed in an oven preset at $150^{\circ} \mathrm{C}$ for $24 \mathrm{~h}$ and then cooled down to room temperature. The healing efficiency was obtained from cut $\&$ heal tests in tensile property measurements with the following equation:

$$
\text { Healing efficiency }=\left(\sigma_{\text {healing }} / \sigma_{\text {original }}\right) \times 100 \%
$$

where $\sigma_{\text {healing }}$ and $\sigma_{\text {original }}$ are tensile strength of healed specimen and original specimen respectively. The self-healing properties of the samples also were investigated using an AIS2100 scanning electron microscope (SEM; Seron Technologies Inc., Gyeonggi-do, Korea). Copolymer specimens of $5 \mathrm{~mm} \times$ $5 \mathrm{~mm}$ were fixed with a carbon tape on the plates for scratch-healing test. A thin scratch was made on the surface of copolymer specimens using a razor blade. The copolymer specimens was coated with gold using an ion coater (HC-21, Hoyeontech, Seongnam, Korea). SEM images were taken after the heat treatment of the scratched specimens of the copolymers in a vacuum oven at $150{ }^{\circ} \mathrm{C}$ for $12 \mathrm{~h}$. The swelling ratios of the copolymer specimens in DMF were measured. It was found that the samples reached the equilibrium swelling after $24 \mathrm{~h}$ at room temperature. Excessive solvent on the surface was removed with filter paper and the fully swollen samples were weighed. The swelling ratios were calculated employing the following equation:

$$
\text { Swelling ratio }(\%)=\left(\left(\mathrm{W}_{\mathrm{s}}-\mathrm{W}_{\mathrm{d}}\right) / \mathrm{W}_{\mathrm{d}}\right) \times 100
$$

where $\mathrm{W}_{\mathrm{s}}$ is the weight of the sample in the swollen state and $\mathrm{W}_{\mathrm{d}}$ that of the dry state of the sample.

\section{Results and Discussion}

\subsection{Synthesis and Characterization of ETPU}

The synthesis pathway of ETPU is shown in Scheme 1. NCO-terminated prepolymers were synthesized from the reaction between MDI and PTMEG1000. When NCO $\%$ reached the theoretical value, the prepared NCO-terminated prepolymer was capped with eugenol to obtain ETPU.

FT-IR spectra of PTMEG1000, prepolymer, eugenol, and ETPU are shown in Figure 1. After PTMEG1000 reacted with MDI, the prepolymer showed strong band at $2270 \mathrm{~cm}^{-1}$ due to the presence of free $\mathrm{N}=\mathrm{C}=\mathrm{O}$ groups of prepolymer. Peaks at $1739 \mathrm{~cm}^{-1}$ and $1600 \mathrm{~cm}^{-1}$ corresponded to stretching vibration of $\mathrm{C}=\mathrm{O}$ and $\mathrm{N}-\mathrm{H}$ bonds in urethane groups, respectively. Compared with prepolymer, the $-\mathrm{OH}$ peak observed in PTMEG1000 at $3462 \mathrm{~cm}^{-1}$ disappeared while N-H stretching vibration at around $3298 \mathrm{~cm}^{-1}$ was observed in FT-IR spectra of prepolymer due to successful synthesis of prepolymer. After the prepolymer reacted with eugenol, the $-\mathrm{N}=\mathrm{C}=\mathrm{O}$ absorption peak at $2270 \mathrm{~cm}^{-1}$ completely disappeared. The peak at $3510 \mathrm{~cm}^{-1}$ corresponding to - $\mathrm{OH}$ of eugenol also disappeared due to the completion of prepolymer capping process with eugenol. ${ }^{1} \mathrm{H}-\mathrm{NMR}$ spectra of ETPU are shown in Figure 2. Signals observed at 7.2 ppm were assigned to urethane group. Peaks at $5.9 \mathrm{ppm}$ and $5.1 \mathrm{ppm}$ corresponded to carbon double bond $\left(-\mathrm{CH}=\mathrm{CH}_{2}\right)$ present in eugenol. Peaks at $1.4 \mathrm{ppm}$ and $3.2 \mathrm{ppm}$ were assigned to $\mathrm{CH}_{2}$ bond from PTMEG. FT-IR analysis results also revealed that the reaction between prepolymer and eugenol was completed. It was postulated that ETPU was successfully synthesized by Scheme 1 . 


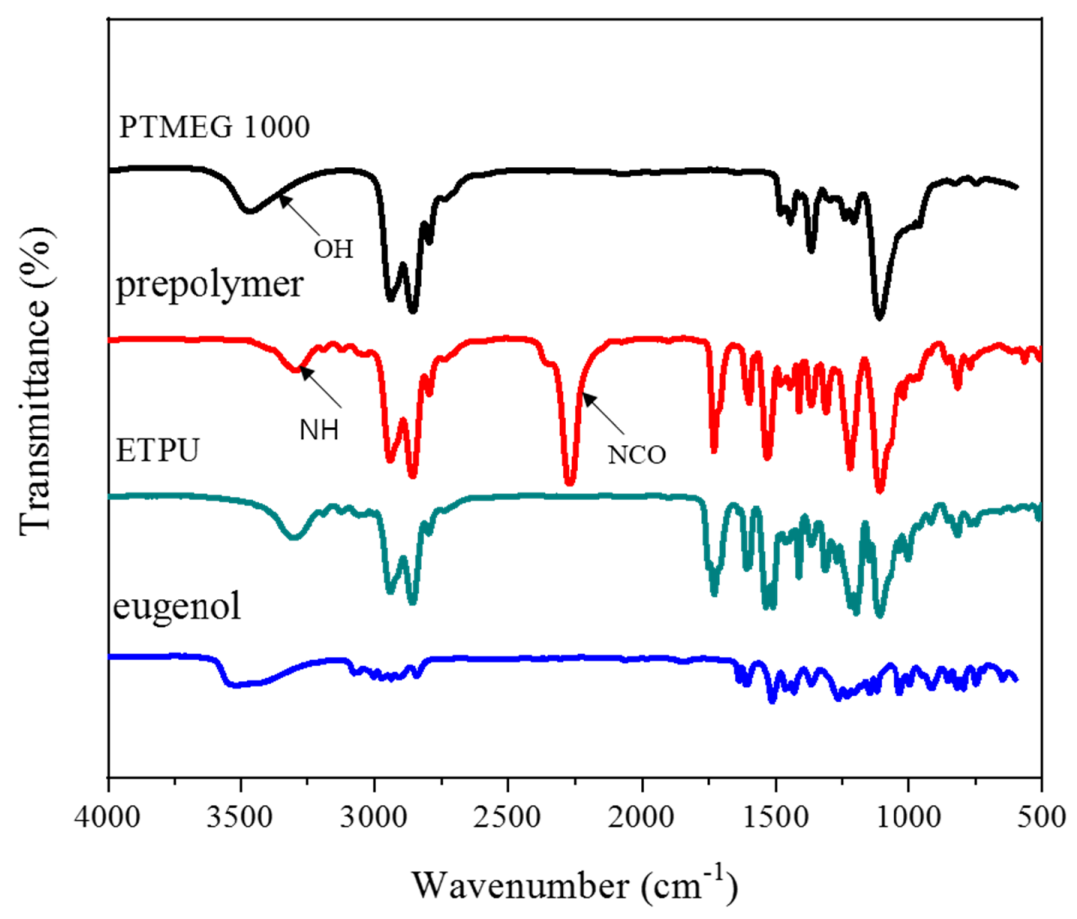

Figure 1. FT-IR spectra of Poly (tetramethylene ether glycol) (PTMEG), prepolymer, eugenol, and eugenol terminated polyurethane prepolymer (ETPU).

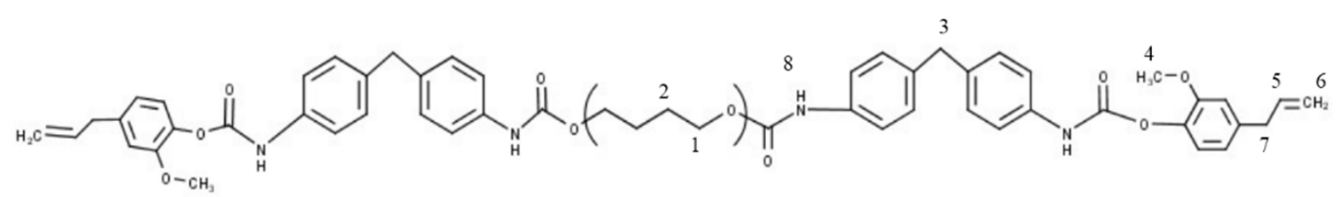

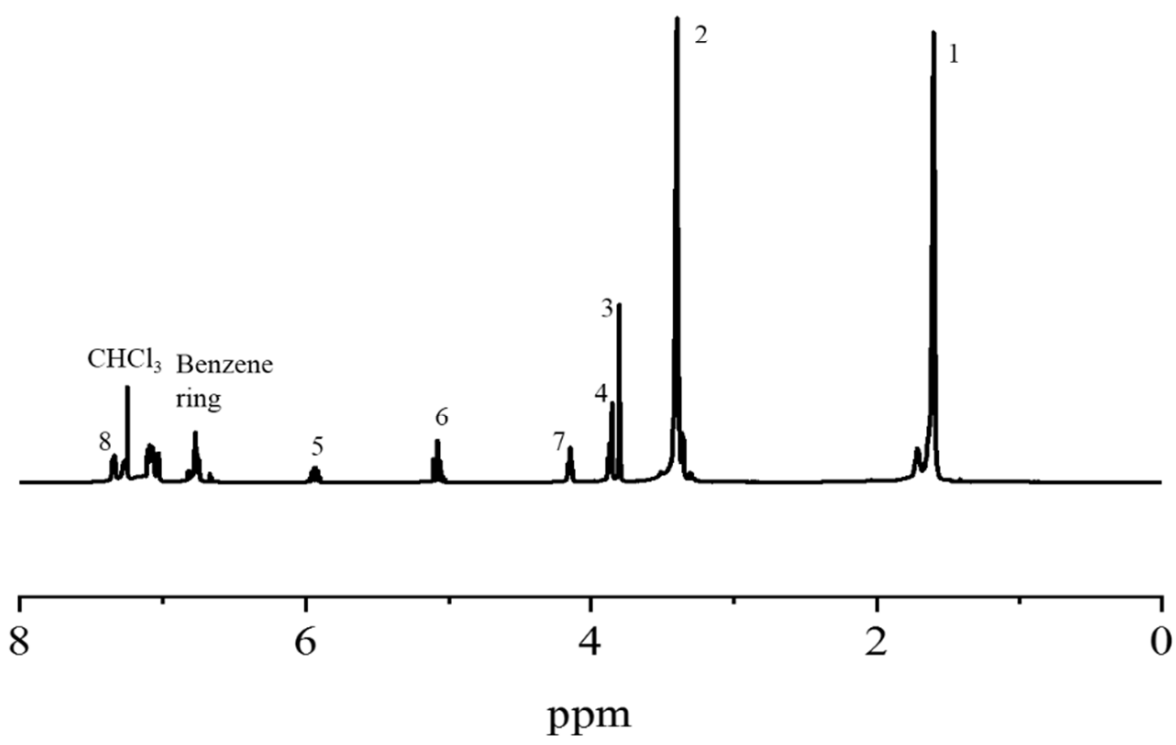

Figure 2. ${ }^{1} \mathrm{H}-\mathrm{NMR}$ spectrum of ETPU.

Variable-temperature FT-IR displaying changes in covalent bonds was used to track the dynamic process of disassociation and reconnection of reversible urethane bonds in ETPU. FT-IR spectra of ETPU scanned from $25^{\circ} \mathrm{C}$ to $180^{\circ} \mathrm{C}$ are shown in Figure 3. As shown in Figure 3b, the -NCO peak at $2270 \mathrm{~cm}^{-1}$ was not observed at $25^{\circ} \mathrm{C}$. However, at temperature above $80^{\circ} \mathrm{C}$, it appeared since the urethane group started reverse reactions at this temperature. When the temperature was increased to $140^{\circ} \mathrm{C}$, the intensity of NCO peak became stronger while that of the $\mathrm{NH}$ peak at $3298 \mathrm{~cm}^{-1}$ was 
decreased, indicating that there was a reversible nature of urethane bonds formed from phenolic hydroxyl and NCO groups [25]. However, when the temperature was further increased to above $150{ }^{\circ} \mathrm{C}$, the -NCO peak started to weaken. The decrease of peak intensity due to -NCO groups can be attributable to the reaction of isocyanate to form allophanate, which is faster than the retro reactions of urethane bonds into hydroxyl and isocyanate groups.

(a)
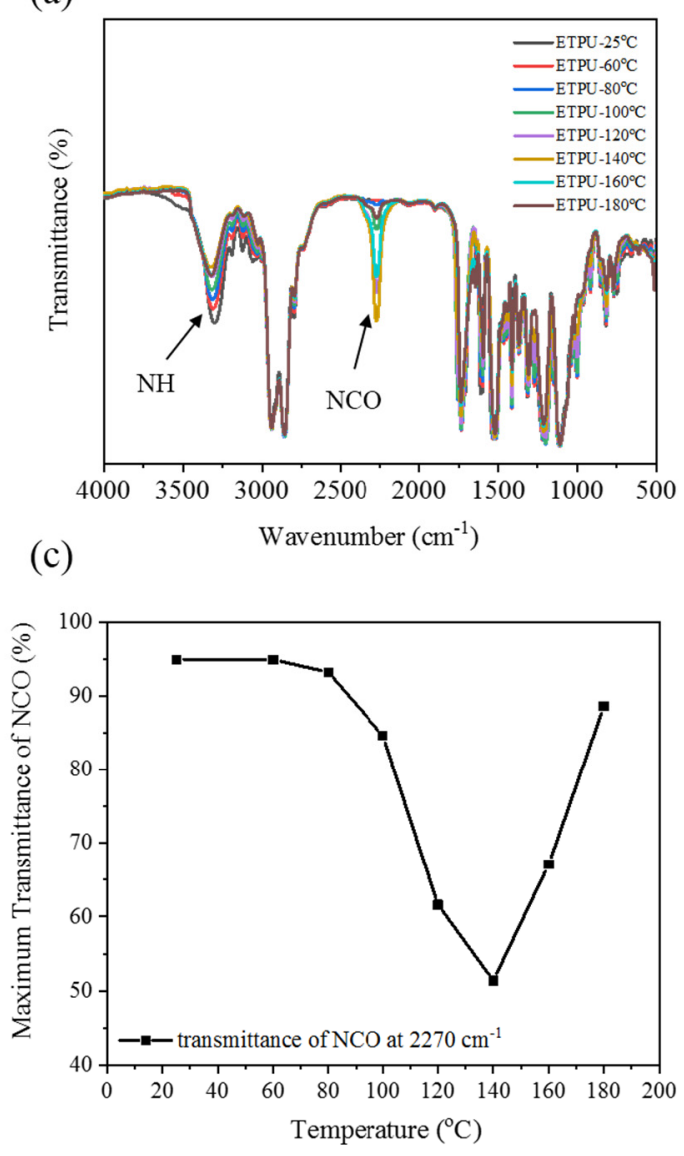

(b)

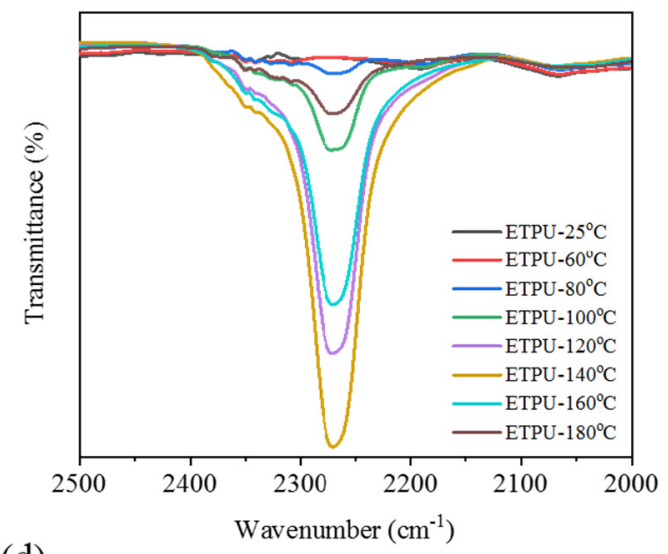

(d)

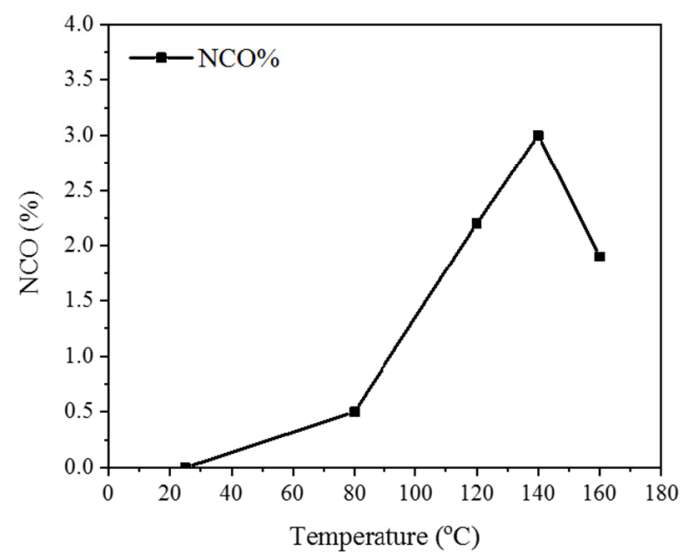

Figure 3. Variable-temperature FT-IR spectra of ETPU with reversible urethane bonds: (a) FT-IR spectra for the copolymers at 4000 500 $\mathrm{cm}^{-1}$; (b)FT-IR spectra at 2000 2500 $\mathrm{cm}^{-1}$; (c) Transmittance change at $2270 \mathrm{~cm}^{-1}$ at elevated temperatures; (d) Change of $\mathrm{NCO} \%$ at elevated temperatures.

In order to confirm the reversible features of urethane bonds in ETPU additionally, NCO contents (\%) of ETPU after heat treatments for $30 \mathrm{~min}$ at elevated temperatures were determined by titration and given in Figure 3d. Change of NCO contents showed the same trends as the change of -NCO peak intensity in Figure 3c. It is suggested that urethane bonds of ETPU are reversible at elevated temperatures investigated as Lee reported [24].

\subsection{Thermal Stability of Copolymers}

The curing behavior of copolymers was measured by DSC. Figure 4a shows DSC curves after curing reaction. As shown in Figure 4a, no more exothermic peaks were observed, confirming that the polymerization was completed. Glass transition temperature $\left(\mathrm{T}_{\mathrm{g}}\right)$ values of copolymers were obtained by DSC analysis. DSC curves showed that copolymers had two glass-transition temperatures at about $-20^{\circ} \mathrm{C}$ and $90^{\circ} \mathrm{C}$ possibly due to soft domain of ETPU and polystyrene phase, respectively. PS only showed one $\mathrm{T}_{\mathrm{g}}$ at $98^{\circ} \mathrm{C}$. $\mathrm{CP} 1, \mathrm{CP} 2$, and $\mathrm{CP} 3$ copolymers showed a soft segment domain $\mathrm{T}_{\mathrm{g}}\left(\mathrm{T}_{\mathrm{gs}}\right)$ at $-12{ }^{\circ} \mathrm{C}$ and the hard segment $\mathrm{T}_{\mathrm{g}}\left(\mathrm{T}_{\mathrm{gh}}\right)$ were increased with the increase of ETPU content. The soft $\mathrm{T}_{\mathrm{gs}}$ was due to the presence of polyurethane chains while the hard $\mathrm{T}_{\mathrm{gh}}$ was due to the polystyrene 
matrix in copolymers. Although the flexible ETPU was introduced to the styrene matrix, the hard $\mathrm{T}_{\mathrm{gh}}$ increased with increasing ETPU content. This is because when the ETPU content is increased, the crosslinking density of copolymers is also increased. The increased crosslinking density might have reduced the molecular mobility of copolymers, thus increasing $\mathrm{T}_{\mathrm{gh}}$.

(a)

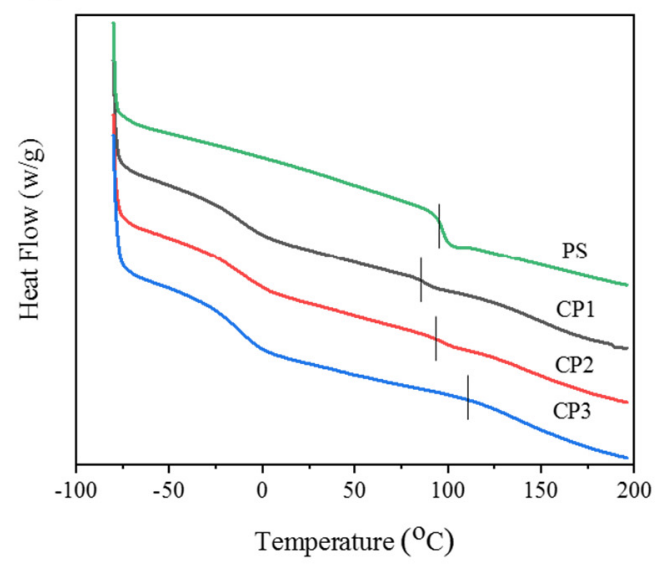

(b)

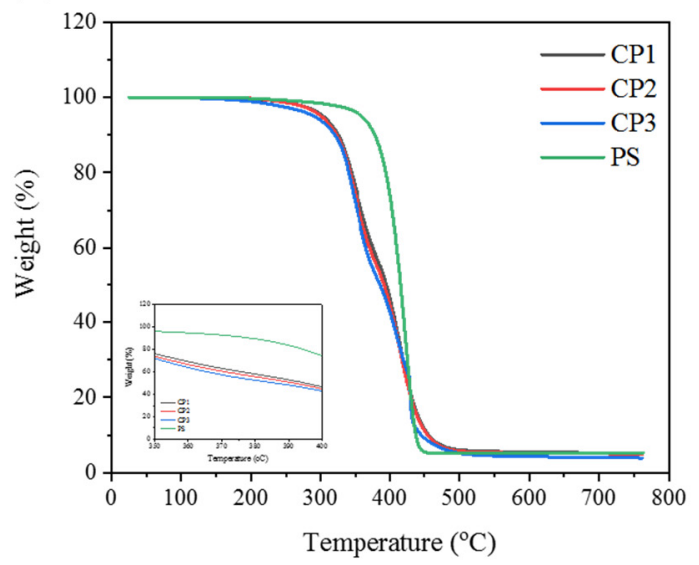

Figure 4. Thermal properties of copolymers: (a) DSC thermograms; (b) TGA curves.

TGA was performed to investigate thermal stability of copolymers. Figure $4 \mathrm{~b}$ shows TGA curves under nitrogen atmosphere. Detailed data are given in Table 2. Pure PS decomposed in one main stage that was visible from $340^{\circ} \mathrm{C}$ to almost $430^{\circ} \mathrm{C}$. It showed the highest thermal stability. The addition of ETPU to PS resulted in displacement of the initial decomposition temperature of obtained materials toward lower temperatures. Meanwhile, an increase in the number of degradation stages was observed together with the presence of ETPU. These copolymers decomposed in two main stages. The first degradation stage appeared at lower temperatures due to decomposition of urethane moieties. Thermal degradation temperature for $5 \%$ weight loss $\left(T_{d} 5 \%\right)$ decreased with increasing content of ETPU. This indicates that, with increasing ETPU content, thermal stability is lowered. Furthermore, the residue content at $700{ }^{\circ} \mathrm{C}$ was decreased with increasing ETPU content.

Table 2. Summary of tensile properties, DMA, and TGA data of copolymers.

\begin{tabular}{|c|c|c|c|c|c|c|c|c|c|}
\hline \multirow{3}{*}{$\begin{array}{c}\text { Sample } \\
\text { codes }\end{array}$} & \multirow{3}{*}{$\begin{array}{c}\text { Tensile } \\
\text { Strength } \\
\text { (MPa) }\end{array}$} & \multirow{3}{*}{$\begin{array}{c}\text { Elongation } \\
\text { at Break } \\
(\%)\end{array}$} & \multirow{3}{*}{$\begin{array}{c}\text { Storage } \\
\text { Modulus at } \\
20^{\circ} \mathrm{C} \text { (MPa) }\end{array}$} & \multicolumn{4}{|c|}{$\mathrm{T}_{\mathrm{g}}\left({ }^{\circ} \mathrm{C}\right)$} & \multirow{3}{*}{$\begin{array}{c}\mathrm{T}_{\mathrm{d} 5 \%} \\
\left({ }^{\circ} \mathrm{C}\right)\end{array}$} & \multirow{3}{*}{$\begin{array}{c}\text { Residues } \\
\text { at } 700{ }^{\circ} \mathrm{C} \\
(\%)\end{array}$} \\
\hline & & & & \multicolumn{2}{|c|}{ DMA } & \multicolumn{2}{|c|}{ DSC } & & \\
\hline & & & & $\mathbf{T}_{\mathrm{gs}}$ & $T_{\text {gh }}$ & $T_{\text {gs }}$ & $T_{\text {gh }}$ & & \\
\hline PS & 7.1 & 10 & 2480 & 0 & 105 & 0 & 98 & 358 & 5.3 \\
\hline $\mathrm{CP} 1$ & 8.4 & 80 & 138 & -16 & 101 & -11 & 90 & 303 & 5.2 \\
\hline $\mathrm{CP} 2$ & 15.4 & 504 & 72 & -16 & 100 & -12 & 101 & 300 & 4.9 \\
\hline $\mathrm{CP} 3$ & 18.8 & 600 & 71 & -16 & 114 & -12 & 109 & 290 & 3.9 \\
\hline
\end{tabular}

\subsection{Mechanical Properties of the Copolymers}

Stress-strain curves for the different copolymers in tensile tests are shown in Figure 5 and tensile properties are summarized in Table 2. It is observed that Young's moduli decrease while tensile strengths and elongations at break increase as the content of ETPU in the copolymers are increased. It is speculated that the incorporation of flexible ETPU segments in the copolymers resulted in the decrease of the modulus. It is of interest to note that the ETPU segments of the copolymers imparted toughening to the copolymers, leading to the improvement of tensile strength and elongation at break. CP1 showed slightly enhanced tensile strength with slightly increased elongation at break, because the ETPU not only act as cross-linker for PS, but also increased the flexibility of copolymers. For the CP2 and $\mathrm{CP} 3$, with the ETPU content increased, the crosslinking density and soft segment content increased, 
resulting in the large improvement of tensile strengths and elongations at break. It is inferred that the increase of ETPU content in the copolymers led to an improvement of chain flexibility, resulting in the increase of the tensile strength and elongation at break efficiently.

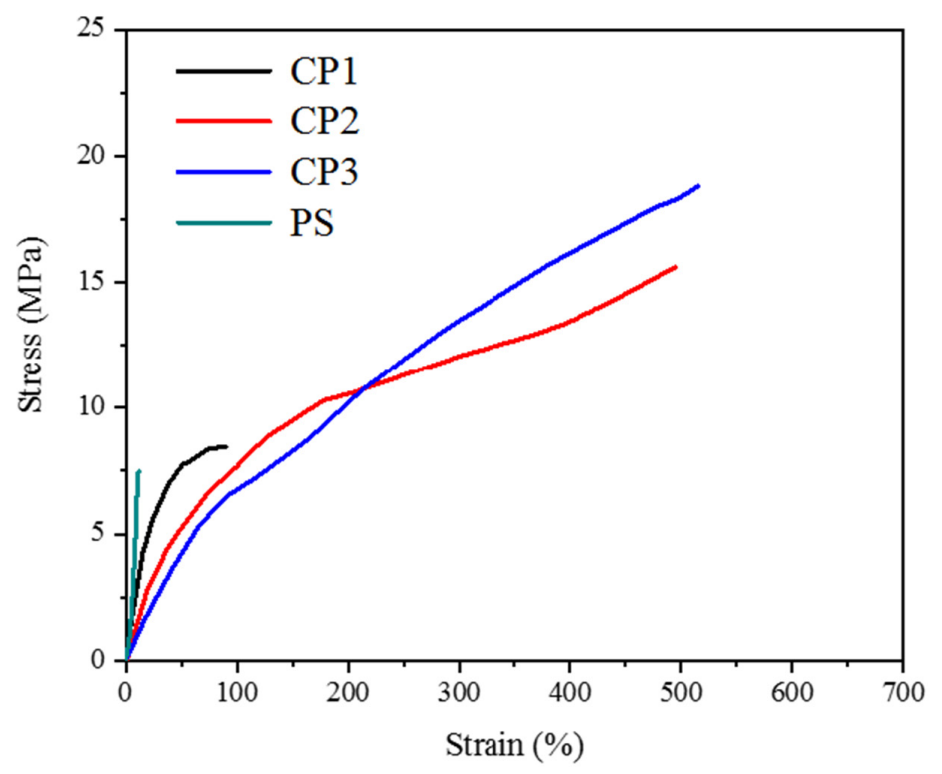

Figure 5. Stress-strain curves of copolymers with different ETPU contents.

\subsection{Dynamic Mechanical Properties}

Dynamic mechanical thermal measurements were used to examine viscoelastic properties of the copolymers. Figure 6 shows temperature dependence of storage modulus and loss factor of the copolymers. PS showed one $\mathrm{T}_{\mathrm{g}}$ at $105^{\circ} \mathrm{C}$. It had the highest storage modulus in Figure 6. Although cross-linked structure was introduced by addition of ETPU to PS, the storage modulus of copolymer was gradually decreased with increasing content of ETPU. This is because of the decrease in rigidity of copolymer caused by ETPU. $T_{g}$ values of copolymers in this study were determined by maximum peak temperatures of tan delta values as shown in Figure $6 \mathrm{~b}$. Copolymers exhibited two $\mathrm{T}_{\mathrm{g}} \mathrm{s}$ due to co-existence of PU segments connected with polystyrene chains. This result coincides with DSC results. $T_{g}$ values of copolymers networks were affected by crosslinking and the content of soft segment. Furthermore, these two peaks showed damping due to transitions of soft PU domain and hard polystyrene matrix. All copolymers were found to have similar $\mathrm{T}_{\mathrm{gs}}$ due to ETPU chains. On the other hand, $\mathrm{T}_{\text {gh }}$ of hard polystyrene chains increased with increasing ETPU content due to the increased crosslinking density of copolymers. Network properties of the crosslinked polymers can be investigated by swelling tests in organic solvents. In order to study the crosslinking of the copolymers, swelling properties of the copolymers in DMF were measured at room temperature. Figure 7 showed the swelling ratios of the copolymers after immersing the specimens in DMF for $24 \mathrm{hrs}$. It was observed that swelling ratios of the copolymers decreased with increase of the ETPU content, implying the crosslinking density increased with increase of the ETPU content. These DMA data and swelling properties of the copolymers demonstrate that ETPU can significantly influence chemical properties as well as the mechanical properties of copolymers by introducing network structures. Table 2 gives summary of tensile properties and thermal properties of copolymers. 
(a)

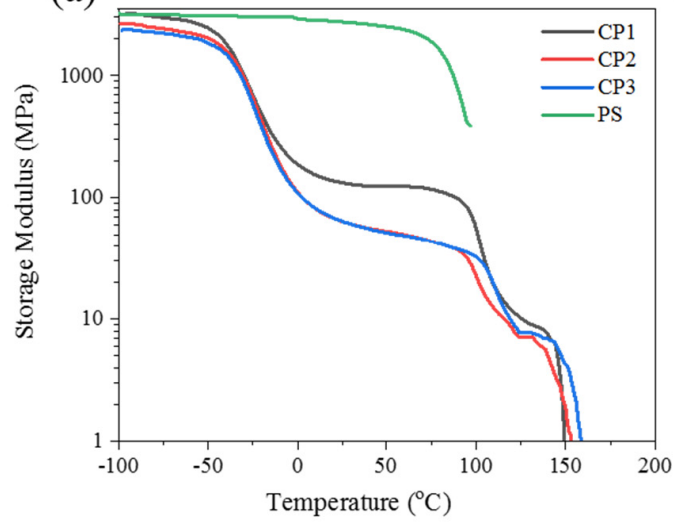

(b)

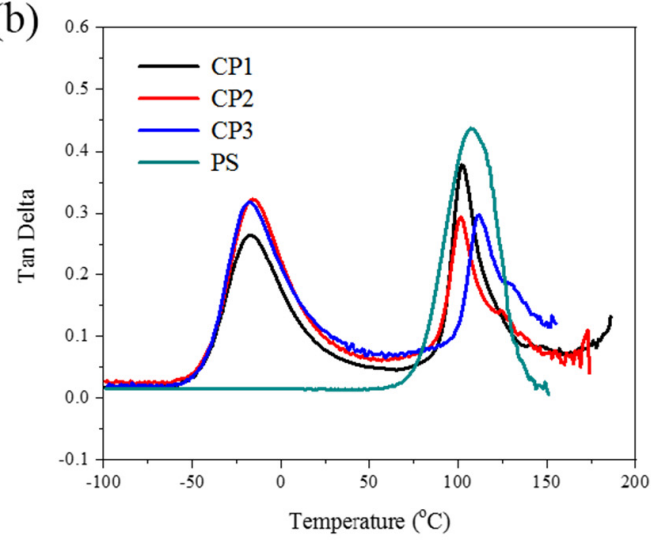

Figure 6. Dynamic mechanical analysis (DMA) curves for copolymers: (a) Storage modulus of copolymers; (b) Tan delta of copolymers.

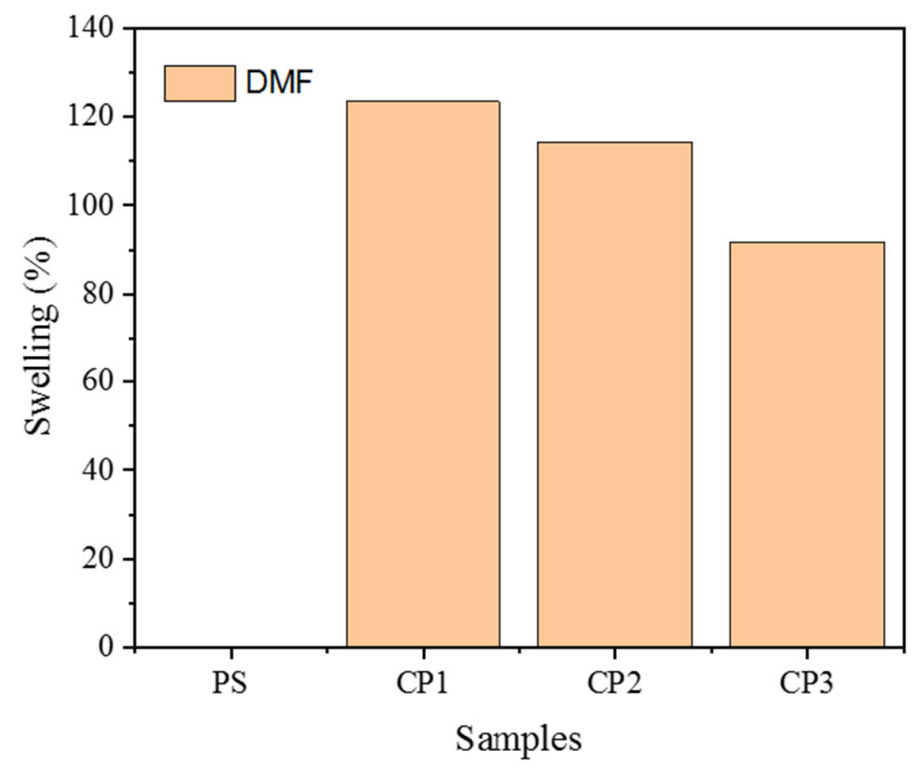

Figure 7. Swelling ratio of the copolymers in DMF at room temperature after $24 \mathrm{hrs}$.

\subsection{Atomic Force Microscopy of Copolymers}

To understand the influence of content of soft segment (ETPU) on the formation of surface topography and heterogeneity of copolymers, AFM analysis was performed to investigate the morphology of copolymers. As shown in Figure 8, 3D phase/height contrast images of copolymers surface were observed. It is known that bright regions represent the hard phase (hard domains) while darker regions represent the soft phase in a segmented polyurethane. The phase indicated the distribution of the copolymers with different hardness. Images showed phase separation due to hard phase of polystyrene and soft phase of ETPU. With increasing ETPU content, soft domains showed increases. In comparison with different contents of ETPU, roughness values of $\mathrm{R}_{\mathrm{q}}$ for CP1, $\mathrm{CP} 2$, and CP3 copolymers were $2.77 \mathrm{~nm}, 3.03 \mathrm{~nm}$, and $10.1 \mathrm{~nm}$, respectively. The roughness increased with increasing content of ETPU. When the content of ETPU was lower (CP1), most phases were hard domains showing lower roughness. With the increase of ETPU content (CP2 and CP3), the number of soft domains increases, leading to increase of roughness. Thus, sharp interface between both phases was observed, indicating increased heterogeneity. These synthesized copolymers were characterized by two-phase morphology consisting of hard segment-rich phase and soft segment-rich phase. It is evident that these synthesized copolymers can be distinguished by the heterogeneous 
character. As shown in Figure 8, styrene and ETPU contents have significantly effects on the structure of copolymer. These results were consistent with DSC data.

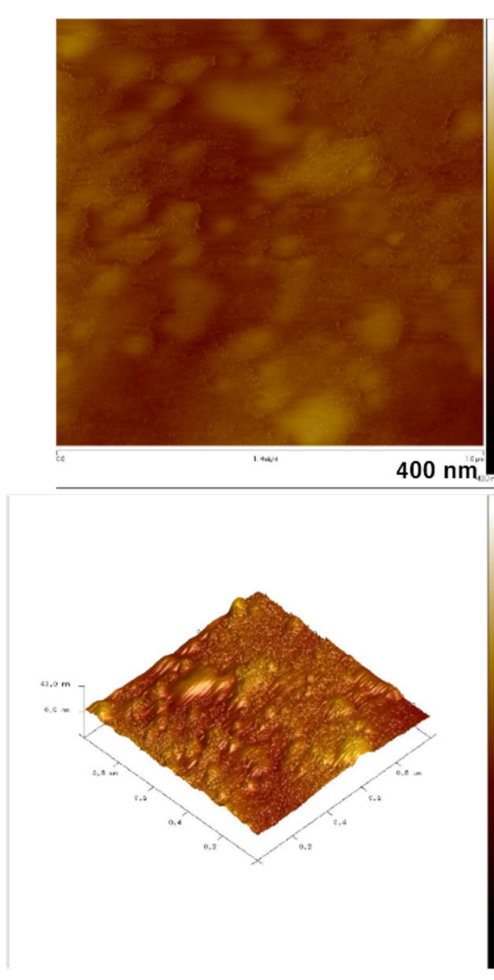

CP1
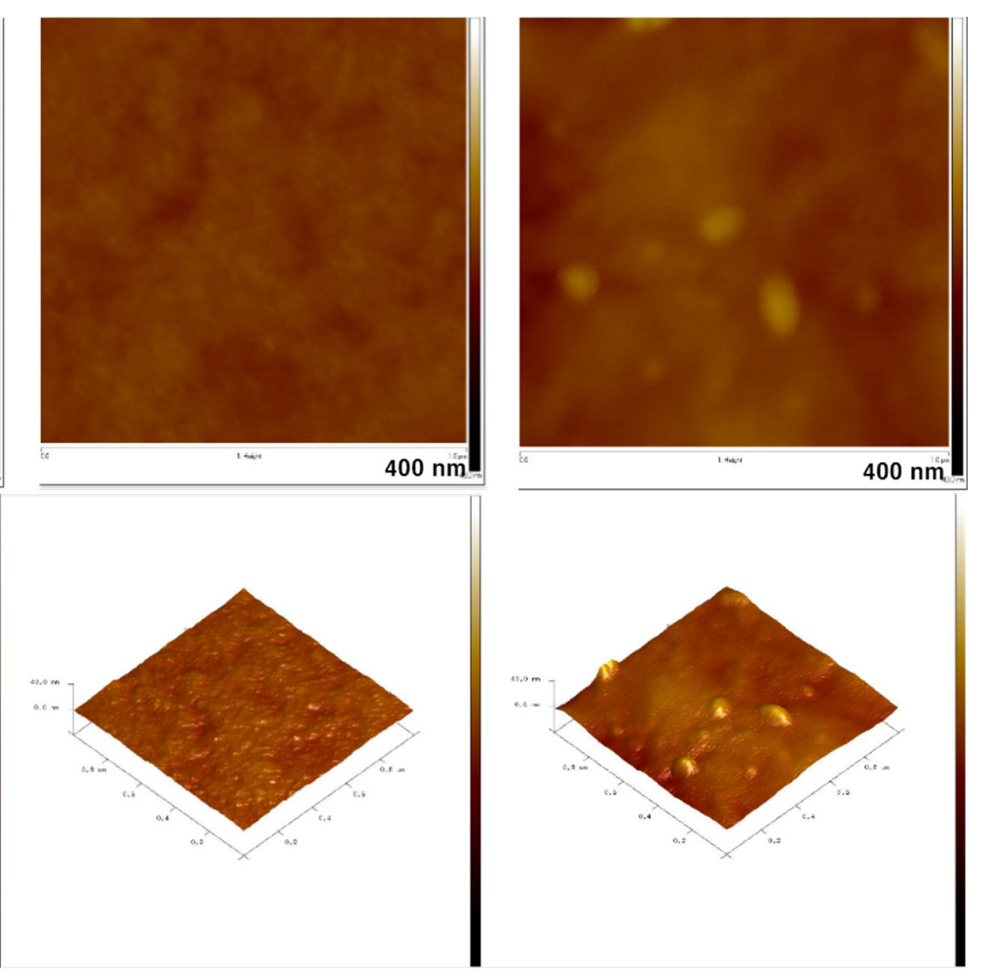

$\mathrm{CP} 2$

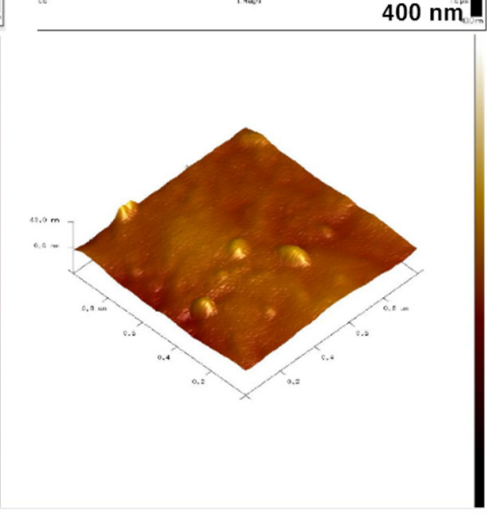

CP3

Figure 8. AFM images of copolymers.

\subsection{Self-healing Properties}

To prove the healing ability, self-healing tests were carried out first by scratching the surface of copolymer. The damage was then thermally treated at $150{ }^{\circ} \mathrm{C}$ for $24 \mathrm{~h}$. Thermal healing of the copolymers were recorded by digital camera. Results are shown in Figure 9. Even after thermal treatment, PS or CP1 did not show healing properties, recovery of scratches. The scratch was seen clearly on the surface due to the absence or very low concentration of urethane bond which showed reversibility with heating (Figure 3). On the other hand, the scratch of CP2 and CP3 showed healing properties after thermal treatment, although the scratch was not completely recovered. At this temperature, the reversible urethane bond disassociated and reconnected, leading to urethane bond reformation, thus showing healing properties on the surface. Based on these results, CP2 and CP3 were used to test the healing efficiency by measuring the mechanical properties. To investigate the self-healing properties further, a scratch healing test was conducted additionally. Here, specimens of CP1 and CP3 were scratched using a razor blade, and the cross-section of the copolymer specimens were observed employing SEM before and after the thermal healing. As shown in Figure 10, we could confirm that the depth of scratch in CP3 decreased largely after the healing while that of CP1 hardly changed.

Mechanical properties are critical for self-healing materials. In this experiment, the sample was cut into half and connected with the original section for self-healing for $24 \mathrm{~h}$ at $150{ }^{\circ} \mathrm{C}$ and $160{ }^{\circ} \mathrm{C}$. In order to investigate self-healing properties, strain-stress curves were acquired for all samples. Figure 11 presents results of self-healing test in mechanical properties of copolymers with different ETPU contents. Data of tensile strength $(\sigma)$ and elongation at break $(\varepsilon)$ before and after the healing are summarized in Table 3. CP2 and CP3 showed thermally healing properties after they were treated at elevated temperature (Figure 11). However, CP1 did not show healing properties due to their low 
contents of reversible urethane groups. Although CP2 and CP3 were not fully restored to their original mechanical properties, it was clear that when the content of ETPU was increased, the efficiency of self-healing was also increased due to reversible urethane unit in the ETPU. Increasing the temperature from $150{ }^{\circ} \mathrm{C}$ to $160^{\circ} \mathrm{C}$ increased the reversible rate and the self-healing efficiency. These results suggest that the content of urethane bonds could affect self-healing properties and that styrene content can influence mechanical properties. Thus, copolymers having higher content of urethane bonds had better self-healing efficiency.

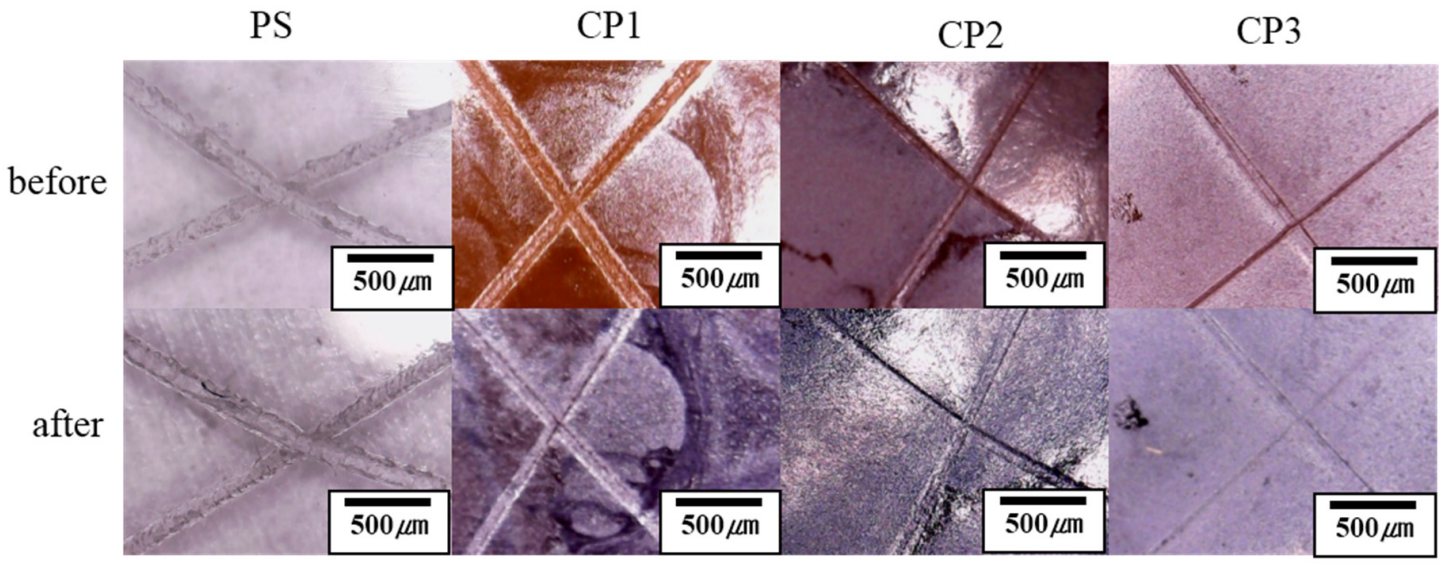

Figure 9. Microscope images of copolymers at $150{ }^{\circ} \mathrm{C}$ before and after thermal treatment.
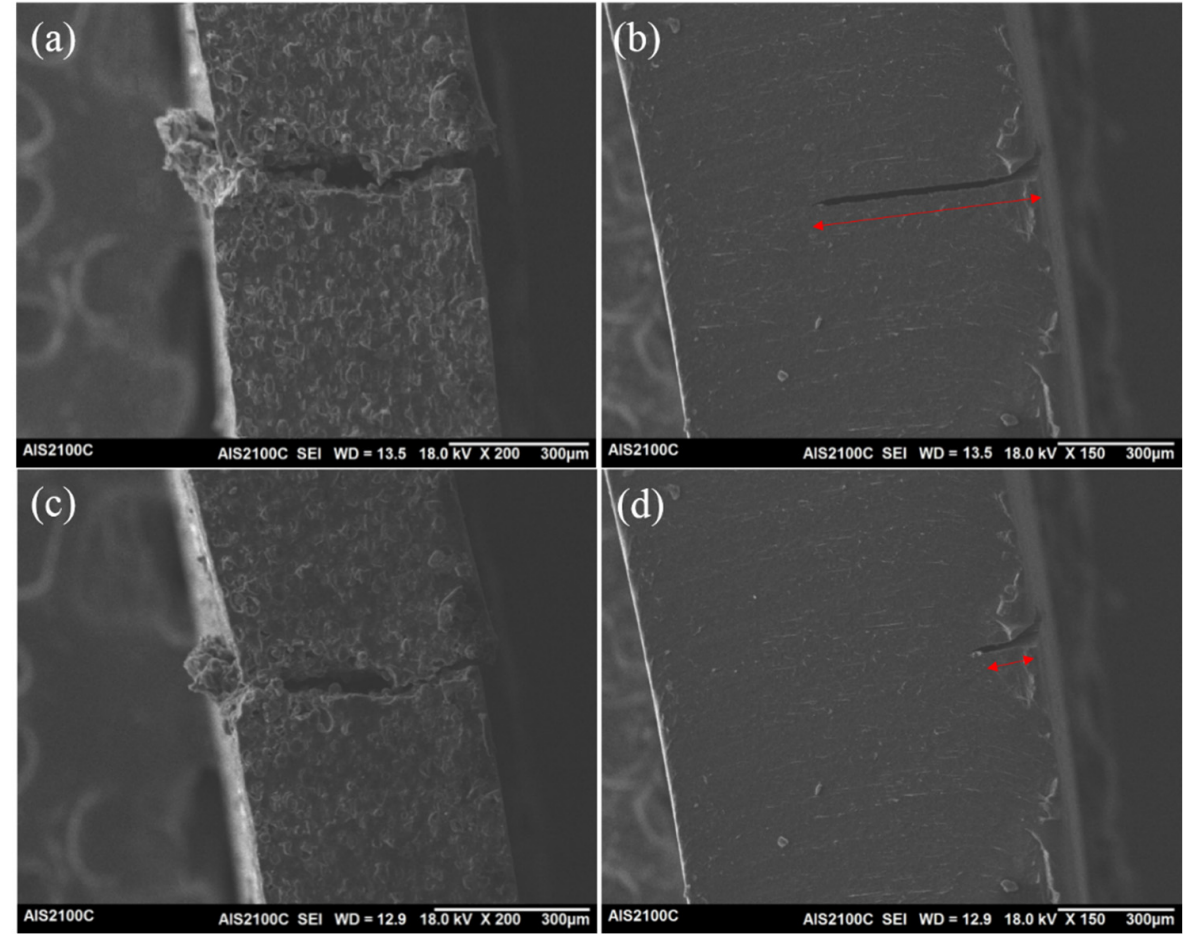

Figure 10. SEM images of copolymers before and after heating treatment: (a) CP1 before healing; (b) CP3 before heated; (c) $\mathrm{CP} 1$ after healing at $150{ }^{\circ} \mathrm{C}$ for $12 \mathrm{hr}$; (d) $\mathrm{CP} 3$ after healing at $150{ }^{\circ} \mathrm{C}$ for $12 \mathrm{hr}$.

The self-healing mechanism of polyurethane can be explained as shown in Figure 12. The healing occurs at soft segment PU domain. Phenolic hydroxyl groups can react with isocyanate and phenolic urethane undergo retro reaction into phenol and isocyanate due to the dynamic natures which had been applied for the temporary masking of isocyanates with phenolic blocking agents through reversible reaction. After polymerization between styrene monomers and ETPU, the urethane bonds from 
the reaction of isocyanate and phenol were incorporated into the copolymers. It is stable at room temperature. However, reversible reactions occurs at elevated temperature. When the temperature cools down, the stable urethane bond forms again $[24,25]$.

(a)

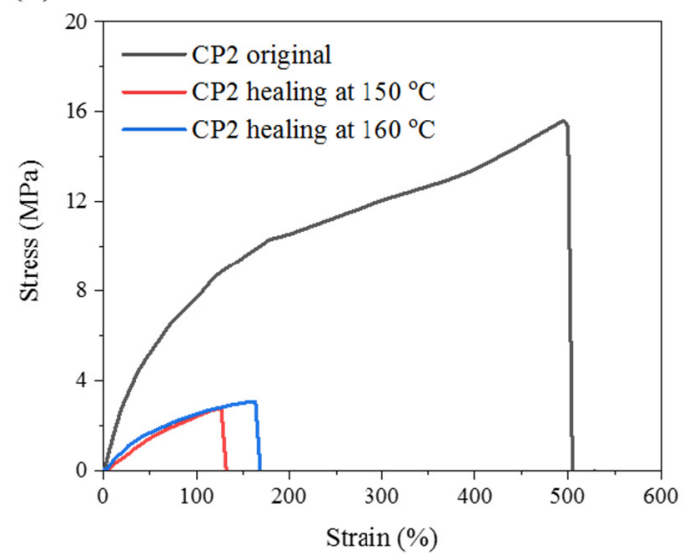

(b)

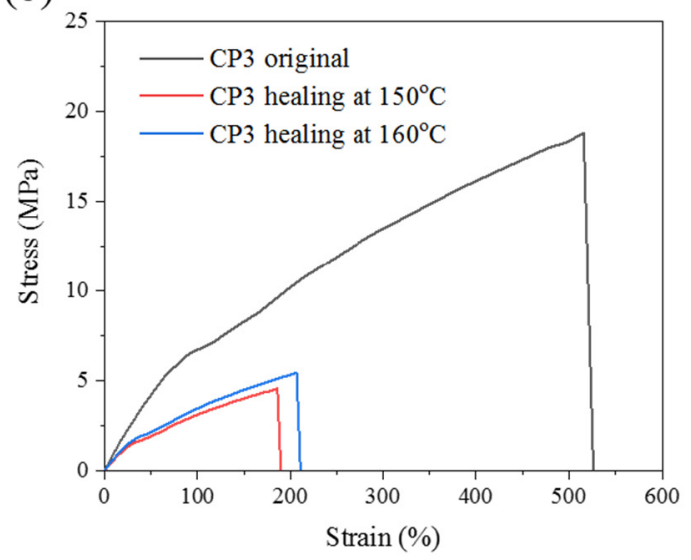

Figure 11. Stress-strain curves of the copolymers after healing at $150{ }^{\circ} \mathrm{C}$ and $160^{\circ} \mathrm{C}$ for $24 \mathrm{hr}$ : (a) $\mathrm{CP} 2$; (b) CP3.

Table 3. Self-healing properties of copolymers at different temperatures.

\begin{tabular}{|c|c|c|c|c|c|c|c|c|}
\hline \multirow{3}{*}{ Sample } & \multirow{2}{*}{\multicolumn{2}{|c|}{ Original }} & \multicolumn{4}{|c|}{ After Healing } & \multicolumn{2}{|c|}{ Healing Efficiency (\%) } \\
\hline & & & \multicolumn{2}{|c|}{$150{ }^{\circ} \mathrm{C}$} & \multicolumn{2}{|c|}{$160^{\circ} \mathrm{C}$} & \multirow[t]{2}{*}{$150^{\circ} \mathrm{C}$} & \multirow[t]{2}{*}{$160^{\circ} \mathrm{C}$} \\
\hline & $\sigma(\mathbf{M P a})$ & $\varepsilon(\%)$ & $\sigma(\mathrm{MPa})$ & $\varepsilon(\%)$ & $\sigma(\mathrm{MPa})$ & $\varepsilon(\%)$ & & \\
\hline PS & 7.1 & 10 & - & - & - & - & - & - \\
\hline $\mathrm{CP} 1$ & 8.4 & 80 & - & - & - & - & - & - \\
\hline $\mathrm{CP} 2$ & 15.6 & 504 & 2.78 & 126 & 3.08 & 163 & 17.8 & 19.7 \\
\hline $\mathrm{CP} 3$ & 18.8 & 600 & 4.6 & 190 & 5.5 & 206 & 24.5 & 29.2 \\
\hline
\end{tabular}
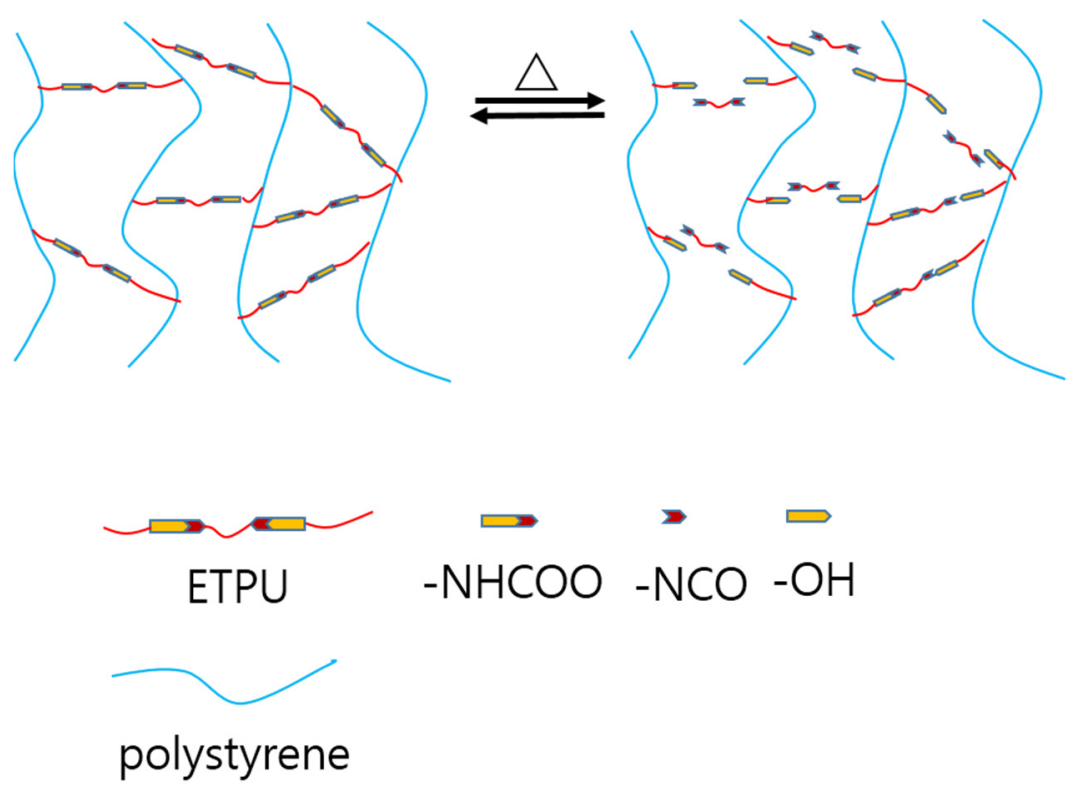

Figure 12. Self-healing mechanism of copolymers.

\section{Conclusions}

In this paper, ETPU, a eugenol-derived bio-based polyurethane prepolymer that contained two polymerizable groups, was successfully prepared and copolymerized with styrene monomers by free 
radical polymerization. ETPU showed NCO peaks at elevated temperatures due to reversible urethane units formed from phenolic hydroxyl group of eugenol and MDI. Results of this study confirmed that the addition of ETPU to PS resulted in the softer and more flexible materials. As a consequence, such copolymers had lower values of glass transition temperature, storage modulus, heat resistivity, and higher values of stress and strain at break compared to PS. Results of this study demonstrate that ETPU can be utilized as an internal, environmentally friendly modifier for vinyl polymers such as PS. The copolymer containing less ETPU showed little self-healing properties. With increasing content of ETPU, tensile strength and elongation at break of copolymers were increased due to more crosslinking by soft PU segment. It was observed that the thermal stability of the copolymer was also improved with increasing ETPU content in the copolymer. Two damping peaks were observed in DMA attributable to transitions of soft PU domain and hard polystyrene matrix, respectively. These copolymers also showed self-healing properties at elevated temperatures due to reversible features of urethane units in ETPU. Their self-healing efficiency also increased with increasing ETPU content in copolymers.

Author Contributions: J.-Y.L., S.-H.L., and D.-S.L. contributed to the manuscript via study design, data analysis and writing. J.-Y.L. and S.-R.S. performed the experiments and analyzed the data.

Funding: This study was supported by the R\&D Center for Valuable Recycling (Global-Top R\&BD Program) of the Ministry of Environment (Project No. 2016002240004).

Conflicts of Interest: The authors declare no conflict of interest.

\section{References}

1. Lligadas, G.; Ronda, J.C.; Galia, M.; Cadiz, V. Renewable polymeric materials from vegetable oils: Aprespective. Materials 2013, 16, 337-343. [CrossRef]

2. Huang, K.; Zhang, P.; Zhang, J.; Li, S.; Li, M.; Xia, J.; Zhou, Y. Preparation of biobased epoxies using tung oil fatty acid-derived C21 diacid and C22 triacid and the study of epoxy properties. Green Chem. 2013, 15, 2466-2475. [CrossRef]

3. Llevot, A.; Grau, E.; Carlotti, S.; Grellier, S.; Cramail, H. From lignin-derived aromatic compounds to novel biobased polymers. Macromo. Papid Commum. 2016, 27, 9-28. [CrossRef] [PubMed]

4. Fache, M.; Viola, A.; Auvergne, R.; Boutevin, B.; Caillol, S. Biobased epoxy thermosets from vanillin-derived oligomers. Eur. Polym. J. 2015, 68, 526-535. [CrossRef]

5. Inna, B.; Bretz, K.; Kabasci, S.; Kopitzky, R.; Springer, A. Succinic acid: A new platform chemical for biobased polymers from renewable resources. Chem. Eng. Technol. 2008, 31, 647-654.

6. Thirukumaran, P.; Shakila, A.; Muthusamy, S. Synthesis and characterization of novel biobased benzoxazines form eugenol. Rsc Adv. 2014, 4, 7959-7966. [CrossRef]

7. Zhang, M.Q.; Rong, M.Z. Design and synthesis of self-healing polymers. Sci. China Chem. 2012, 55, 648-676. [CrossRef]

8. Chen, S.; Mahmood, N.; Beiner, M.; Binder, W.H. Self-healing materials from V-and H-shaped supramolecular architectures. Angew. Chem. Int. Ed. 2015, 54, 10188-10192. [CrossRef]

9. Beck, J.B.; Multistimuli, S.J. Multiresponsive metallo-supramocular polymers. J. Am. Chem. Soc. 2003, 125, 13922-13923. [CrossRef]

10. Cui, Y.L.; Tan, M.; Zhu, A.D.; Guo, M.Y. Non-covalent interaction cooperatively induced stretchy, tough and stimuli-responsive polyurethane-urea supramolecular (PUUS) hydrogels. J. Mater. Chem. B 2015, 3, 2834-2841. [CrossRef]

11. Chang, K.; Jia, H.; Gu, S.Y. A transparent, highly strethchable, self-healing polyurethane based on disulfide bonds. Eur. Polym. J. 2019, 112, 822-831. [CrossRef]

12. Yuan, C.E.; Rong, M.Z.; Zhang, M.Q.; Zhang, Z.P.; Yuan, Y.C. Self-healing of polymers via synchronous covalent bond fisson/radical recombination. Chem. Mater. 2011, 23, 5076-5081. [CrossRef]

13. Deng, G.H.; Tang, C.M.; Li, H.Y.; Jiang, H.F.; Chen, Y.M. Covalent cross-linked polymer gels with reversible sol-gel transition and self-healing properties. Macromolecules 2010, 43, 1191-1194. [CrossRef] 
14. Oh, C.R.; Lee, D.I.; Park, J.H.; Lee, D.S. Thermally healale and recyclable graphene-nanoplate/epoxy composites via an in-situ Diels-Alder reaction on the graphene-nanoplate surface. Polymers 2019, 11, 1057. [CrossRef] [PubMed]

15. Chang, D.K.; Chul, O.; Chang, J.Y. The use of a thermally reversible bond for molecular imprinting of silica spheres. J. Am. Chem. Soc. 2002, 124, 14838-14839.

16. Liu, T.; Hao, C.; Zhang, S.; Yang, X.N. A self-healable high glass transition temperature bioepoxy material based in vitrimer chemistry. Macromolecules 2018, 51, 5577-5585. [CrossRef]

17. Ling, L.; Li, J.; Zhang, G.; Sun, R.; Wong, C.P. Self-healing and shape memory linear polyurethane based on disulfide linkages with excellent mechanical property. Macromol. Res. 2018, 26, 365-373. [CrossRef]

18. Karami, Z.; Zohuriaan-Mehr, M.J.; Rostami, A. A bio-based thrmo-healable non-isocyanate polyurethane DA network in comparison with its epoxy counterpart. J. CO2 Util. 2017, 18, 294-302. [CrossRef]

19. Zhu, K.; Song, Q.; Chen, H.; Hu, P. Thermally assisted self-healing polyurethane containing carboxyl groups. J. Appl. Polym. Sci. 2018, 135, 1-7. [CrossRef]

20. Feng, L.; Yu, Z.; Bian, Y.; Lu, J.; Shi, X.; Chai, C. Self-healing behavior of polyurethanes based on dual actions of thermos-reversible Diels-Alder reaction and thermal movement of molecular chains. Polymer 2017, 124, 48-59. [CrossRef]

21. Lin, C.; Sheng, D.; Liu, X.; Xu, S.; Ji, F.; Dong, L.; Zhou, Y.; Yang, Y. NIR induced self-healing electrical conductivity polyurethane/ graphene nanocomposites based on Diels-Alder reaction. Polymer 2018, 140, 150-157. [CrossRef]

22. Kim, S.M.; Jeon, H.; Shin, S.H.; Park, S.A.; Jegal, J.; Heang, S.Y.; Oh, D.X.; Park, J. Superior toughness and fast self-healing at room temperature engineered by transparent elastomers. Adv. Mater. 2018, 30, 1705145. [CrossRef] [PubMed]

23. Yangisawa, Y.; Nan, Y.; Okuro, K.; Aida, T. Mechanically robust, readily repairable polymers via tailored noncovalent cross-linking. Science 2018, 359, 72-76. [CrossRef] [PubMed]

24. Lee, D.W.; Kim, H.N.; Lee, D.S. Introduction of reversible urethane bonds based on vanilly alcohol for efficient self-healing of polyurethane elastomers. Molecules 2019, 24, 2201. [CrossRef] [PubMed]

25. Cao, S.; Li, S.H.; Li, M.; Xu, L.N.; Ding, H.Y.; Xia, J.L.; Huang, K. A thermal self-healing polyurethane thermoset based on phenolic urethane. Polym. J. 2017, 49, 775-781. [CrossRef]

26. Simon, J.; Barla, F.; Kelemen-Haller, A.; Farkas, F.; Kraxner, M. Thermal stability of polyurethanes. Chromatographia 1988, 25, 99-106. [CrossRef]

27. Telysheva, G.; Dobele, G.; Dizhbite, D.; Rossinska, G.; Jurkjane, V. Characterization of the transformations of lignocellulosic structures upon degradation in planted soil. J. Anal. Pyrol. 2007, 79, 52-60. [CrossRef]

28. Philp, J. OECD policies for bioplastics in the content of a bioeconomy. Ind. Biotechnol. 2014, 10, 19-21. [CrossRef]

29. Sun, L.; Singh, S.; Joo, M.; Simmones, B.A.; Auer, M. Non-invasive imaging of cellulose microfibril orientation within plant cell walls by polarized Raman microspectroscopy. Biotechnol. Bioeng. 2016, 113, 82-90. [CrossRef]

30. Sabaa, M.W.; Mohamed, R.R. Organic thermal stabilizers for rigid poly (vinyl chloride). Part 8, Eugenol (4-allyl-2-methoxy-phenol). Polym. Degrad. Stab. 2007, 92, 587-595. [CrossRef]

31. Harvey, B.G.; Sahagun, C.M.; Guenthner, A.J.; Groshens, T.J.; Cambrea, L.R.; Reams, J.T.; Mabry, J.M. A high-performance renewable thermosetting resin derived from eugenol. ChemSusChem 2014, 7, 1964-1969. [CrossRef] [PubMed]

32. Dai, J.; Yang, S.; Teng, N.; Liu, Y.; Liu, X.; Zhu, J.; Zhao, J. Synthesis of eugenol-based silicon-containing benzoxazines and their applications as bio-based organic coatings. Coatings 2018, 8, 88. [CrossRef]

33. Wan, J.T.; Gan, B.; Li, C.; Molina-Aldareguia, J.; Kalali, E.N.; Wang, X.; Wang, D.Y. A sustainable, eugenol-derived epoxy resin with high biobased content, modulus, hardness and low flammability: Synthesis, curing kinetics and structure-property relationship. Chem. Eng. 2016, 284, 1080-1093. [CrossRef]

34. Maul, J.; Frushour, B.G.; Kontoff, J.R.; Eichenauer, H.; Ott, K.-H.; Schade, C. Polystyrene and Styrene Copolymers. In Ullmann's Encyclopedia of Industrial Chemistry; Wiley-VCH: Weinheim, Germany, 2007. [CrossRef]

35. Xiang, K.; Wang, X.; Huang, G.; Zheng, J.; Huang, J.; Li, G. Thermal ageing behavior of styrene-butadiene random copolymer: A study on the ageing mechanism and relaxation properties. Polym. Degrad Stab. 2012, 9, 1704-1715. [CrossRef] 
36. Xiang, K.; Wang, X.; Huang, G.; Zheng, J.; Huang, J.; Li, G. Thermogravimetric studies of styrene-butadiene rubber (SBR) after accelerated thermal aging. J. Anal. Calorim. 2014, 115, 247-254. [CrossRef]

37. Munteanu, B.S.; Brebu, M.; Vasile, C. Thermal behaviour of binary and ternary copolymers containing acrylonitrile. Polym. Degrad Stab. 2013, 98, 1889-1897. [CrossRef]

38. Adelia, F.F.M.; Mariana, A.S.; Vieira, M.G.A.; Marisa, M.B. Epoxidation of modified natural plasticizer obtained from rice fatty acids and application on polyvinylchloride films. J. Appl. Polym. Sci. 2013, 127, 3543-3549.

39. Dave, V.J.; Patel, H.S. Synthesis and characterization of interpenetrating polymer networks from transesterified castor oil based polyurethane and polystyrene. J. Chem. Soc. 2017, 21, 18-24. [CrossRef]

40. Quintana, R.; Persenaire, O.; Lemmouchi, Y.; Sampson, J.; Martin, S.; Bonnaud, L.; Dubois, P. Enhancement of cellulose acetate degradation under accelerated weathering by plasticization with ecofriendly plasticizers. Polym. Degrad Stab. 2013, 98, 1556-1562. [CrossRef]

41. Klinger, M.; Tolbod, L.P.; Ogilby, P.R. Influence of a novel castroloil-derived additive on the mechanical properties and oxygen diffusivity of polystyrene. J. Appl. Polym. Sci. 2010, 118, 1643-1650.

42. Gupta, A.P.; Ahmad, S.; Dev, A. Modification of novel bio-based resin-epoxidized soybean oil by conventional epoxy resin. Polym. Eng. Sci. 2011, 51, 1087-1091. [CrossRef]

(C) 2019 by the authors. Licensee MDPI, Basel, Switzerland. This article is an open access article distributed under the terms and conditions of the Creative Commons Attribution (CC BY) license (http://creativecommons.org/licenses/by/4.0/). 